\title{
Palbociclib induces cell senescence and apoptosis of gastric cancer cells by inhibiting the Notch pathway
}

\author{
HENGTAI BI $^{1}$, JUAN SHANG ${ }^{2}$, XIAO ZOU $^{3}$, JING XU $^{4}$ and YUMEI HAN ${ }^{5}$ \\ ${ }^{1}$ Department of Pharmacy, Weifang People's Hospital, Weifang, Shandong 261041; \\ ${ }^{2}$ Department of Pharmacy, The People's Hospital of Bin Zhou, Bin Zhou, Shandong 256600; \\ Departments of ${ }^{3}$ Oncology and ${ }^{4}$ Neurology, The First People's Hospital of Tai'an, Tai'an, Shandong 271000; \\ ${ }^{5}$ Department of General Surgery, Weifang People's Hospital, Weifang, Shandong 261041, P.R. China
}

Received July 31, 2020; Accepted April 8, 2021

DOI: $10.3892 / \mathrm{ol} .2021 .12864$

\begin{abstract}
Palbociclib (PD0332991), a selective cyclin-dependent kinase 4/6 (CDK4/6) inhibitor, has been reported to exert anticancer activity in some cancers, including gastric cancer (GC). However, the role of palbociclib in GC remains largely unknown. The present study aimed to investigate the effects of palbociclib on the progression of GC and the potential mechanisms underlying its effects. The colony formation, proliferation, senescence, as well as apoptosis and cell cycle progression of AGS and HGC-27 cells following treatment with palbociclib were analyzed using colony formation assays, MTT assays, senescence-associated $\beta$-galactosidase (SA- $\beta$-gal) staining and flow cytometry, respectively. The protein expression levels of Bax, Caspase-3, Bcl-2, p16, p21, p53, Notch1, Notch2 and hairy and enhancer of split 1 (Hes1) were measured in AGS and HGC-27 cells using western blotting. Moreover, the mRNA expression levels of Notch1, Notch2 and Hes1 in AGS and HGC-27 cells were determined by reverse transcription-quantitative PCR. In the present study, palbociclib significantly inhibited cell proliferation and induced cell senescence, cell cycle arrest and apoptosis in both cell lines in a dose-dependent manner. Additionally, palbociclib significantly increased the expression levels of Bax, Caspase-3, p16, p21 and p53, whilst decreasing the expression of Bcl-2, Notch1, Notch2 and Hes1 in AGS and HGC-27 cells. Furthermore, the Notch pathway activator Jagged-1/FC reversed the effects of palbociclib on cell proliferation, apoptosis, senescence and cell cycle progression. These findings demonstrated that palbociclib could inhibit proliferation and induce senescence, cell cycle arrest and apoptosis in GC cells by inhibiting the Notch pathway.
\end{abstract}

Correspondence to: Dr Yumei Han, Department of General Surgery, Weifang People's Hospital, 151 Guangwen, Kuiwen, Weifang, Shandong 261041, P.R. China

E-mail: hanyumei112@163.com

Key words: gastric cancer, palbociclib, cell cycle, senescence, apoptosis, Notch pathway

\section{Introduction}

Gastric cancer (GC) was reported the fifth most commonly diagnosed malignancy and the third leading cause of cancer-related deaths worldwide in 2018 (1). East Asia has the highest incidence and mortality rates of GC (2). Although advances have been made in GC treatment in recent years, the 5-year survival rate for patients with advanced GC is $<15 \%(3,4)$. Thus, the identification of novel drugs and therapeutic targets for GC treatment is urgently needed.

Palbociclib (PD0332991) is a potent and highly selective inhibitor of cyclin-dependent kinase 4/6 (CDK4/6) (5), which was approved by the Food and Drug Administration in 2015 for the treatment of advanced breast cancer (6). In addition, increasing evidence demonstrates that palbociclib also plays an important role in the treatment of multiple cancer types, including hepatocellular carcinoma, head and neck cancer, colorectal cancer and GC (7-10). However, the potential role of palbociclib in GC has not been extensively analyzed.

The Notch signaling pathway is evolutionarily conserved and can direct cell fate decisions by regulating proliferation, cell cycle progression, apoptosis, differentiation, senescence and metastasis $(11,12)$. Previous studies have demonstrated that the Notch pathway plays an important role in tumorigenesis $(13,14)$. Moreover, activation of the Notch pathway could promote the progression of GC (15). Jena et al (16) reported that CDK6 kinase activity plays a key role in the onset of $\mathrm{T}$ cell acute lymphoblastic leukemia via Notch1 activation in a mouse model. However, whether palbociclib affects GC by modulating the Notch pathway remains unknown. The present study aimed to determine the effect, if any, of palbociclib on the Notch pathway in GC.

\section{Materials and methods}

Cell culture and drug treatment. The AGS and HGC-27 GC cell lines were obtained from the American Type Culture Collection. All cells were cultured in RPMI-1640 medium (Sigma-Aldrich; Merck KGaA) containing 10\% fetal bovine serum (Gibco; Thermo Fisher Scientific, Inc.) and $1 \%$ penicillin/streptomycin (HyClone; Cytiva) and maintained at $37^{\circ} \mathrm{C}$ in a humidified incubator containing $5 \% \mathrm{CO}_{2}$. Palbociclib was 
purchased from Pfizer (PD0332991), dissolved in DMSO and added into the culture medium at the indicated concentration. Cells were exposed to drug treatment for 2 days at $37^{\circ} \mathrm{C}$, unless otherwise indicated. Cells were randomly divided into seven groups: i) Control (0 $\mu \mathrm{M}$ palbociclib); ii) $0.25 \mu \mathrm{M}$ palbociclib; iii) $0.5 \mu \mathrm{M}$ palbociclib; iv) $1 \mu \mathrm{M}$ palbociclib; v) $2 \mu \mathrm{M}$ palbociclib; vi) $4 \mu \mathrm{M}$ palbociclib and vii) $0.5 \mu \mathrm{M}$ palbociclib $+10 \mu \mathrm{M}$ Jagged-1/FC. The activator of Notch pathway (Jagged-1/FC) was supplied by Abcam.

MTT assay. The proliferation of AGS and HGC-27 cells was measured using an MTT assay. After $48 \mathrm{~h}$ of palbociclib treatment, cells ( $2 \times 10^{3}$ cells/well) were seeded in 96-well plates for 24, 48, 72, 96 and $120 \mathrm{~h}$ at room temperature. At each time point, a volume of $20 \mu \mathrm{l}$ MTT solution $(5 \mathrm{mg} / \mathrm{ml})$ was then added to each well, and the cells were incubated for an additional $4 \mathrm{~h}$. Finally, the absorbance at $495 \mathrm{~nm}$ was measured using a microplate reader (Bio-Rad Laboratories, Inc.).

Colony formation assay. Colony-forming capability was measured using a colony formation assay. After $48 \mathrm{~h}$ of palbociclib treatment, AGS and HGC-27 cells were seeded into 6 -well plates at a density of $1 \times 10^{3}$ cells/well and cultured with complete medium for 2 weeks. The cells were then fixed with $4 \%$ paraformaldehyde for $20 \mathrm{~min}$ at room temperature and stained with $0.1 \%$ crystal violet for $25 \mathrm{~min}$ at room temperature. The stained colonies were counted under a light microscope.

Cell apoptosis assay. Apoptosis was assessed in AGS and HGC-27 cells using an Annexin V-EGFP apoptosis detection kit (cat. no. KGA101; Nanjing KeyGen Biotech Co., Ltd.). After $48 \mathrm{~h}$ of palbociclib treatment, AGS and HGC-27 cells were collected and resuspended in binding buffer. Annexin V-EGFP (5 $\mu \mathrm{l})$ and propidium iodide $(5 \mu \mathrm{l}$, PI; Beyotime Institute of Biotechnology) were added to the cell suspension and maintained at room temperature in the dark for $15 \mathrm{~min}$. Early and late apoptosis in the second and fourth quadrants were detected using FACSCalibur, using CellQuest Pro software (version 5.1; BD Biosciences).

Cell cycle analysis. Cell cycle progression was evaluated using PI staining. After $48 \mathrm{~h}$ of palbociclib treatment, AGS and HGC-27 cells were harvested and washed in PBS. Subsequently, the cells were fixed in cold $75 \%$ ethanol at $4^{\circ} \mathrm{C}$ overnight. After washing with PBS twice, the cells were stained with PI (40 $\mu \mathrm{g} / \mathrm{ml}$; Beyotime Institute of Biotechnology) containing RNase A (20 ng/ml; Sigma-Aldrick; Merck KGaA) for $30 \mathrm{~min}$ at $37^{\circ} \mathrm{C}$ in the dark. Cell cycle distribution was then determined using FACSCalibur (BD Biosciences), using ModFit LT software (version 3.1; Verity Software House).

Senescence-associated $\beta$-galactosidase (SA- $\beta$-gal) staining. Cell senescence was measured using a Senescence $\beta$-Galactosidase Staining kit (Beyotime Institute of Biotechnology), as previously described (17). After 5 days of palbociclib treatment, AGS and HGC-27 cells were fixed with $4 \%$ paraformaldehyde for $10 \mathrm{~min}$ at room temperature, then incubated overnight at $37^{\circ} \mathrm{C}$ in freshly prepared $\beta$-gal staining solution $(1 \mathrm{mg} / \mathrm{ml} \mathrm{X-Gal,} 5 \mathrm{mM}$ potassium ferricyanide, $5 \mathrm{mM}$ potassium ferrocyanide, $40 \mathrm{mM} \mathrm{Na}{ }_{2} \mathrm{HPO}_{4}, 150 \mathrm{mM} \mathrm{NaCl}$ and $2 \mathrm{mM} \mathrm{MgCl} 2$ ). The senescent cells were observed and counted under a light microscope.

Reverse transcription-quantitative PCR (RT-qPCR). After $48 \mathrm{~h}$ of palbociclib treatment, total RNA from AGS and HGC-27 cells was extracted using TRIzol ${ }^{\circledR}$ (Invitrogen; Thermo Fisher Scientific, Inc.) and reverse transcribed into cDNA using TransScript One-Step gDNA Removal and cDNA Synthesis SuperMix (TransGen Biotech Co., Ltd.). The conditions for RT were as follows: $25^{\circ} \mathrm{C}$ for $5 \mathrm{~min}, 55^{\circ} \mathrm{C}$ for $20 \mathrm{~min}$ and $85^{\circ} \mathrm{C}$ for $5 \mathrm{~min}$. qPCR was then performed using the TransStart TipTop Green qPCR SuperMix (TransGen Biotech Co., Ltd.). The primer sequences (Sangon Biotech Co., Ltd.) were as follows: i) Notch1 sense, 5'-GACATCACG GATCATATGGA-3' and antisense, 5'-CTCGCATTGACC ATTCAAAC-3'; ii) Notch2 sense, 5'-TGCCAAGCTCAG TGGTGTTGTA-3' and antisense, 5'-TGCTAGGCTTTGTGG GATTCAG-3'; iii) Hes1 sense, 5'-ACGTGCGAGGGCGTT AATAC-3' and antisense, 5'-ATTGATCTGGGTCATGCA GTTG-3'; iv) $\beta$-actin sense, 5'-AGGCACCAGGGCGTGAT-3' and antisense, 5'-GCCCACATAGGAATCCTTCTGAC-3'. The following thermocycling conditions were used for qPCR: $95^{\circ} \mathrm{C}, 10 \mathrm{sec}$ (denaturation); $55^{\circ} \mathrm{C}, 30 \mathrm{sec}$ (annealing); $72^{\circ} \mathrm{C}$, $30 \mathrm{sec}$ (extension) for 40 cycles. Relative expression levels were calculated using the $2^{-\Delta \Delta \mathrm{Cq}}$ method (18) and normalized to the internal reference gene $\beta$-actin.

Western blot analysis. After $48 \mathrm{~h}$ of palbociclib treatment, total protein was extracted from AGS and HGC-27 cells using RIPA lysis buffer (Beyotime Institute of Biotechnology), as previously described (19) and maintained at $-80^{\circ} \mathrm{C}$ until use. Protein concentrations were determined using a bicinchoninic acid assay kit (Thermo Fisher Scientific, Inc.). Protein samples (50 $\mu \mathrm{g})$ were resolved by SDS-PAGE on $10 \%$ gels, then transferred onto a polyvinylidene difluoride membrane and blocked for $1.5 \mathrm{~h}$ in $5 \%$ skimmed milk at room temperature. The membranes were then incubated with primary antibodies against p16 (1:1,000; cat. no. ab220800), p21 (1:1,000; cat. no. ab109199), p53 (1:1,000; cat. no. ab131442), Bax (1:1,000; cat. no. ab77566) Caspase-3 (1:500; cat. no. ab4051), Bcl-2 (1:1,000; cat. no. ab196495), Notch1 (1:500; cat. no. ab52301), Notch2 (1:500; cat. no. ab8926), Hes1 (1:1,000; cat. no. ab221788) and $\beta$-actin (1:1,000; cat. no. ab115777) (all from Abcam) overnight at $4^{\circ} \mathrm{C}$. Subsequently, the membranes were incubated with the horseradish peroxidase-conjugated secondary antibody (1:5,000; cat. no. 5961; Cell Signaling Technology, Inc.) for $2 \mathrm{~h}$ at room temperature. Finally, the protein bands were visualized with an ECL reagent (Amersham Biosciences) and analyzed using Quantity One 1-D Analysis software (Bio-Rad Laboratories, Inc.). The density of the protein bands was quantitated using ImageJ software (version 1.8.0; National Institutes of Health).

Statistical analysis. Data are presented as the mean \pm SD of three independent measurements. Statistical analysis was performed using GraphPad Prism 8.0 (GraphPad Software, Inc.) and SPSS 22.0 software (IBM Corp.). One-way ANOVA followed by Tukey's post hoc test was used to assess the differences between the groups. $\mathrm{P}<0.05$ was considered to indicate a statistically significant difference. 
A

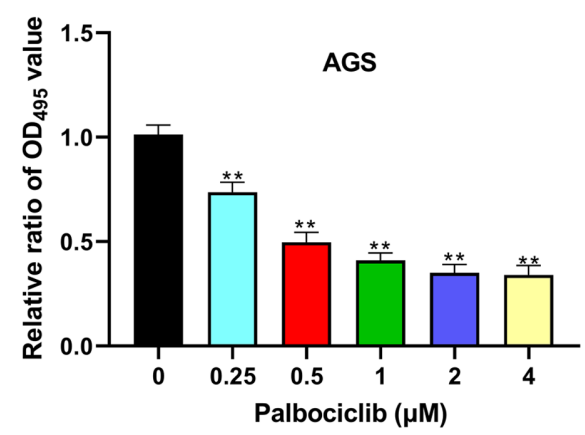

B

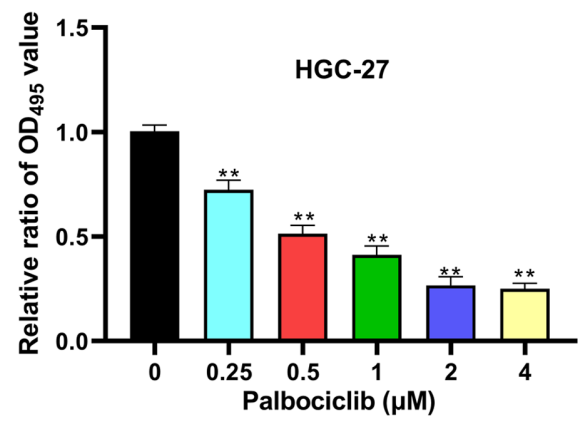

Figure 1. Different doses of palbociclib inhibits the proliferation of AGS and HGC-27 cells in a dose-dependent manner. Proliferation of (A) AGS cells and (B) HGC-27 cells following palbociclib treatment. ${ }^{* *} \mathrm{P}<0.01$ vs. palbociclib $(0 \mu \mathrm{M})$.
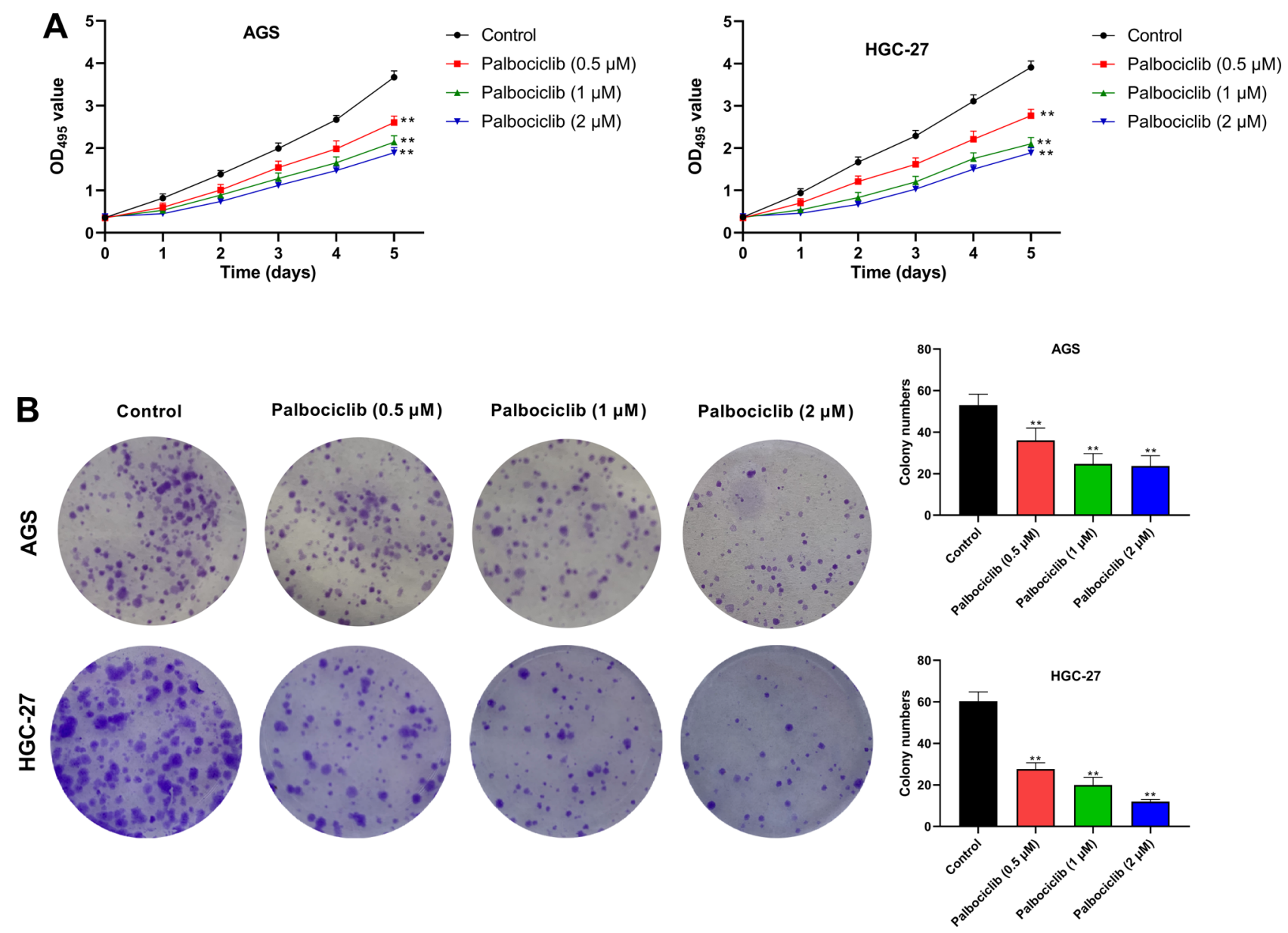

Figure 2. Palbociclib inhibits the proliferation of AGS and HGC-27 cells. (A) Proliferation of AGS and HGC-27 cells was detected at different time points following palbociclib treatment. (B) Clone numbers of AGS and HGC-27 cells following palbociclib treatment. ${ }^{* *} \mathrm{P}<0.01$ vs. control. OD, optical density.

\section{Results}

Palbociclib inhibits the proliferation of AGS and HGC-27 cells. To evaluate the effect of palbociclib on cell proliferation, AGS and HGC-27 cells were treated with different doses of palbociclib. Palbociclib significantly inhibited the proliferation of AGS and HGC-27 cells in a dose-dependent manner (Fig. 1). Palbociclib was used at concentrations of $0.5,1$ and $2 \mu \mathrm{M}$ for subsequent experiments. The results of MTT assays indicated that palbociclib $(0.5,1$ and $2 \mu \mathrm{M})$ significantly inhibited the proliferation of AGS and HGC-27 cells at day 1, 2, 3, 4 and 5, compared with the control group $(\mathrm{P}<0.01)$ (Fig. 2A). Moreover, in colony formation assays, the number of AGS and HGC-27 cell clones were significantly reduced by palbociclib in a dose-dependent manner $(\mathrm{P}<0.01)$ (Fig. 2B). Thus, palbociclib inhibited the proliferation of AGS and HGC-27 cells.

Palbociclib promotes the apoptosis of AGS and HGC-27 cells. As shown in Fig. 3A, palbociclib $(0.5,1$ and $2 \mu \mathrm{M})$ significantly increased the apoptosis of AGS and HGC-27 
A
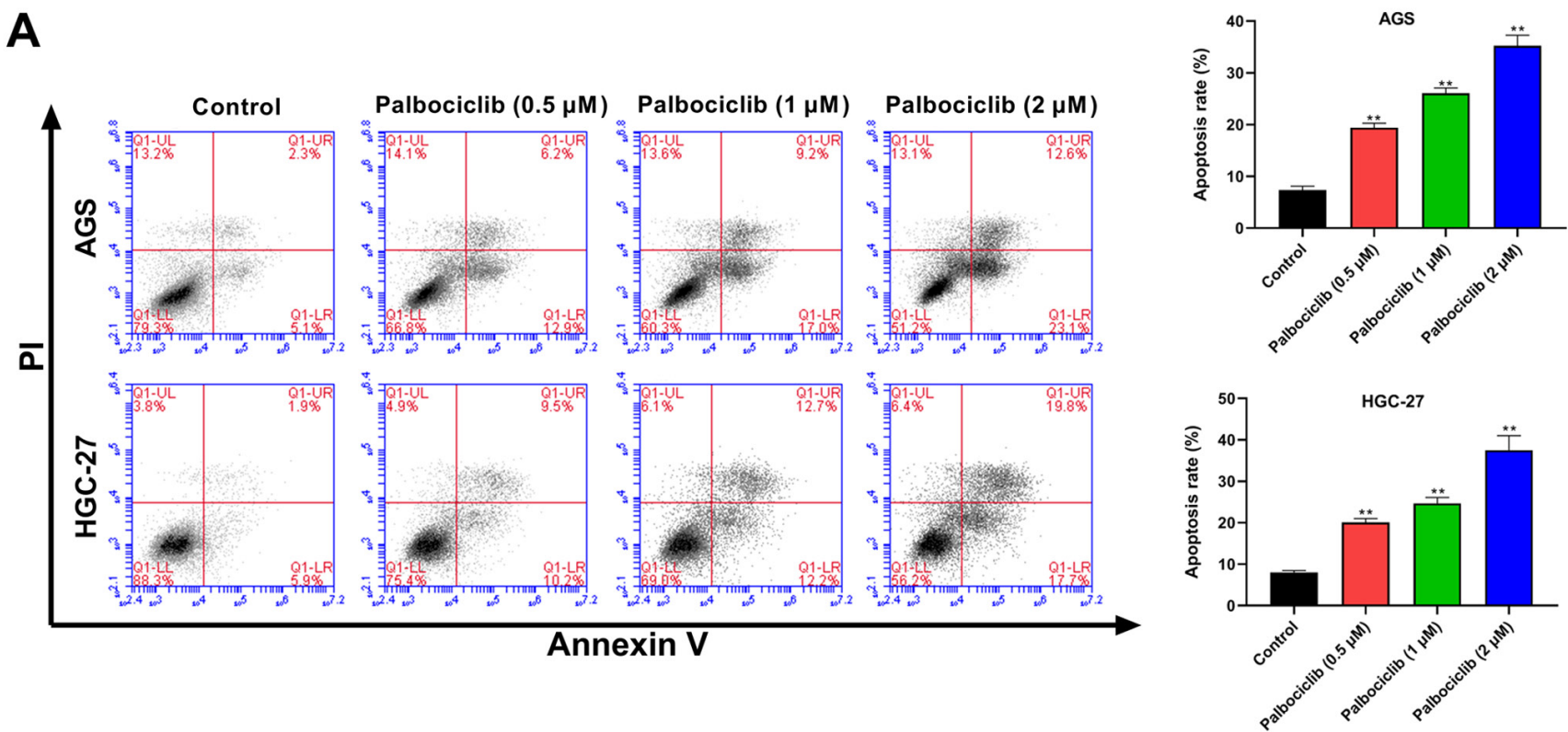

B
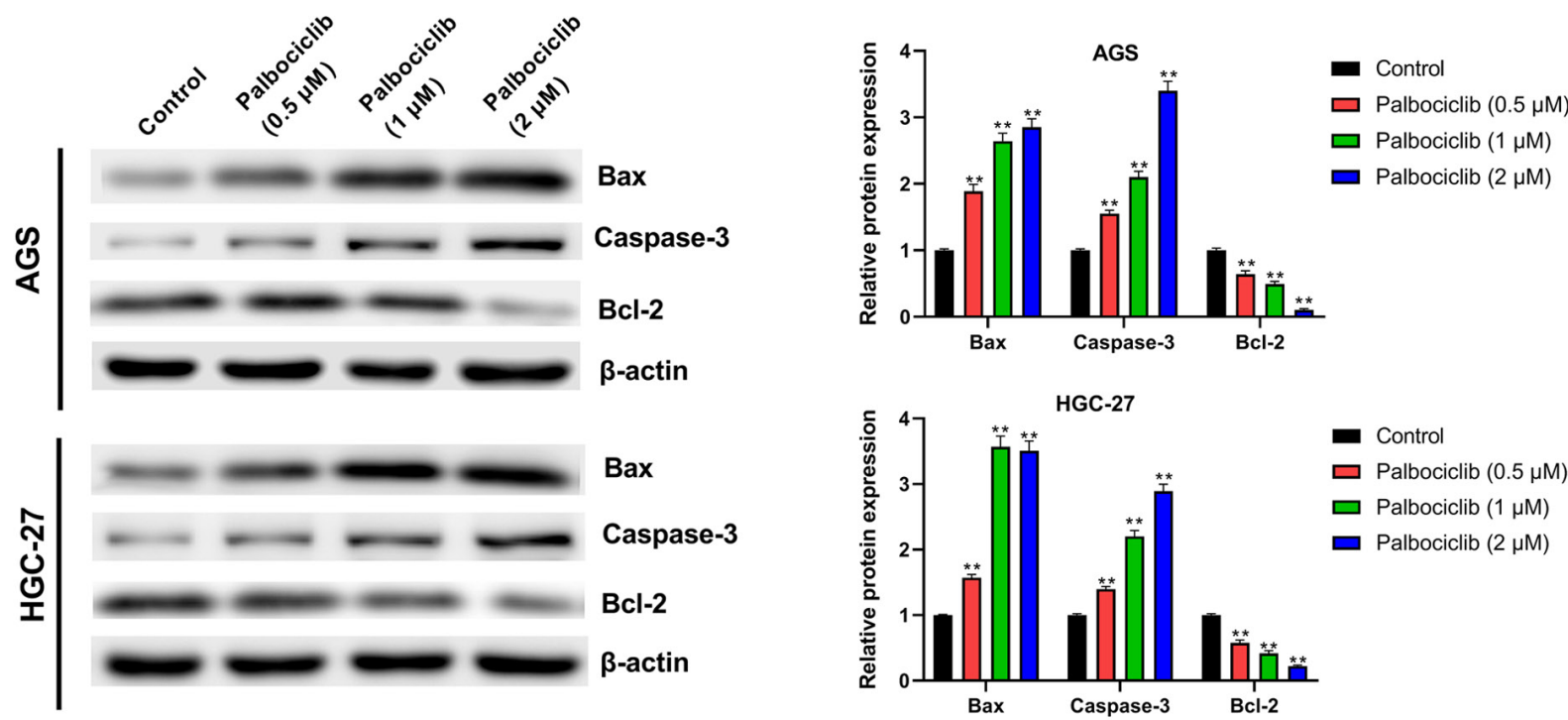

Figure 3.Palbociclibpromotes the apoptosis of AGS and HGC-27 cells.(A) Apoptosis of AGS and HGC-27 cells afterpalbociclib treatment.(B)Proteinexpression levels of Bax, Caspase-3 and Bcl-2 were measured in AGS and HGC-27 cells following palbociclib treatment. ${ }^{* *} \mathrm{P}<0.01$ vs. control. PI, propidium iodide.

cells relative to the control group $(\mathrm{P}<0.01)$. To confirm the effect of palbociclib on apoptosis, the expression of apoptosis-related proteins was detected using western blotting. Palbociclib significantly reduced Bcl-2 expression in AGS and HGC-27 cells in a dose-dependent manner compared with the control group, but increased the expression levels of Bax and Caspase-3 ( $\mathrm{P}<0.01$ in all cases; Fig. 3B). This finding suggested that palbociclib promoted the apoptosis of AGS and HGC-27 cells.

Palbociclib induces cell senescence and cell cycle arrest in AGS and HGC-27 cells. As shown in Fig. 4A, palbociclib $(0.5,1$ and $2 \mu \mathrm{M})$ significantly increased the senescence of AGS and HGC-27 cells compared with the control group $(\mathrm{P}<0.01)$. In addition, the cell cycle analysis revealed that palbociclib $(0.5,1$ and $2 \mu \mathrm{M})$ increased the proportion of cells in the $\mathrm{G}_{1}$ phase in both AGS and HGC-27 cells, but decreased the proportion of cells in the $\mathrm{S}$ phase $(\mathrm{P}<0.01)$ (Fig. 4B), suggesting that palbociclib could induce an accumulation of AGS and HGC-27 cells in the $\mathrm{G}_{1}$ phase of the cell cycle. Furthermore, palbociclib significantly increased the expression levels of p16, p21 and p53 in AGS and HGC-27 cells compared with the control group, and this effect was dose-dependent $(\mathrm{P}<0.01$ in all cases; Fig. $4 \mathrm{C})$. These results indicated that palbociclib induced cell senescence and cell cycle arrest in AGS and HGC-27 cells.

Palbociclib inhibits the Notch signaling pathway in AGS and HGC-27 cells. As shown in Fig. 5, palbociclib $(0.5 \mu \mathrm{M})$ significantly reduced the mRNA and protein expression levels of Notch1, Notch2 and Hes1 in AGS and HGC-27 cells compared with the control group ( $\mathrm{P}<0.01$ in all cases). However, compared with the palbociclib $(0.5 \mu \mathrm{M})$ group, the mRNA and protein expression levels of Notch1, Notch2 and Hes1 in AGS and 

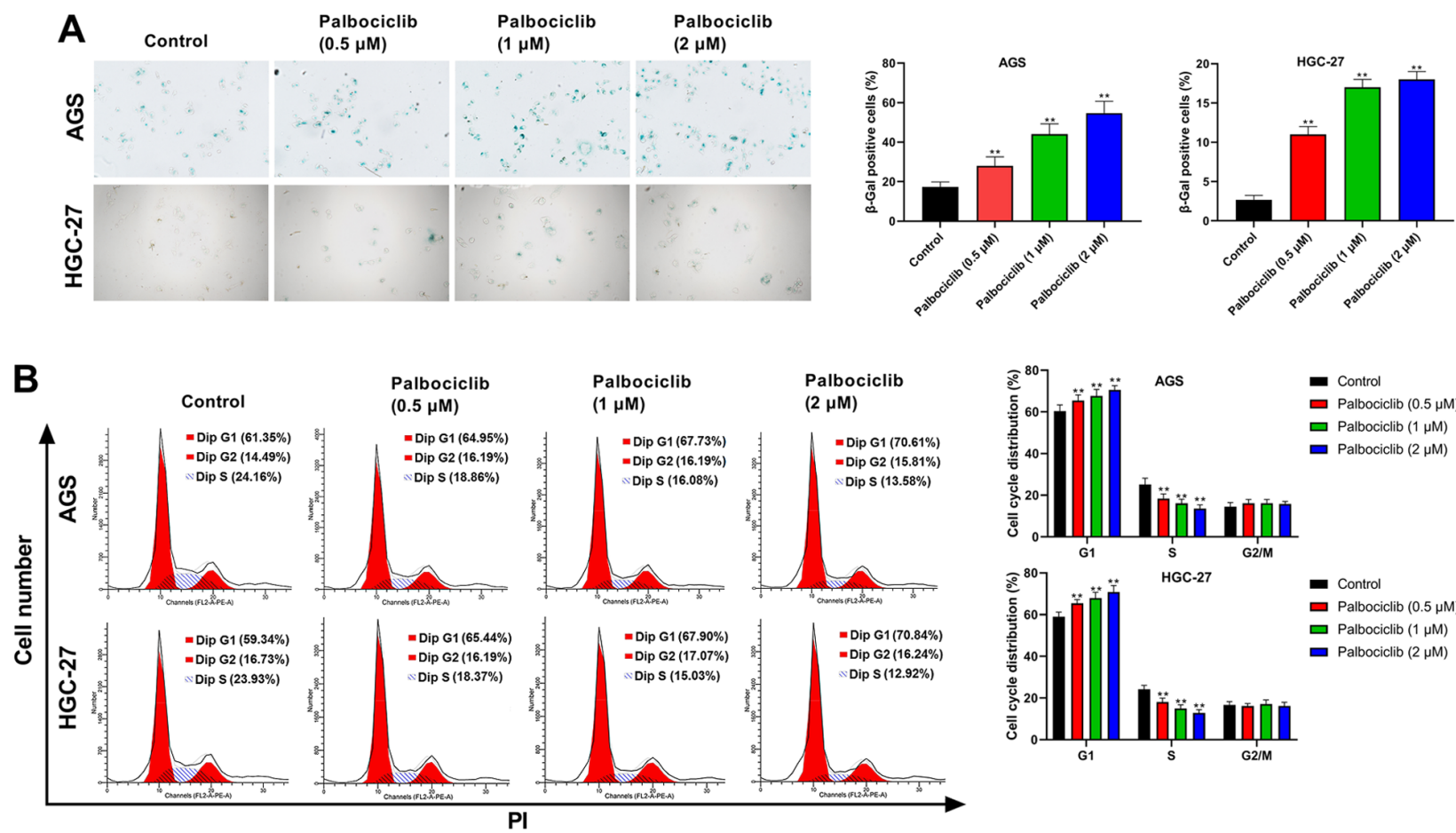

C
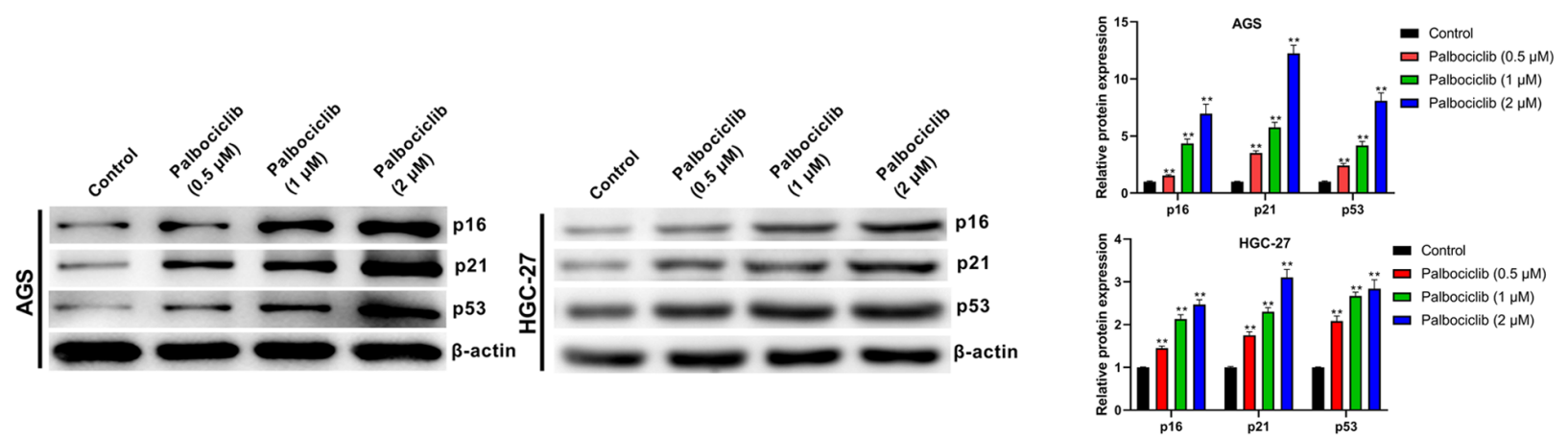

Figure 4. Palbociclib induces cell senescence and cell cycle arrest in AGS and HGC-27 cells. (A) Senescence of AGS and HGC-27 cells after palbociclib treatment was detected by senescence associated- $\beta$-gal staining (magnification, x200). (B) Cell cycle progression in AGS and HGC-27 cells following palbociclib treatment. (C) Expression levels of p16, p21 and p53 were measured in AGS and HGC-27 cells following palbociclib treatment. ${ }^{* *} \mathrm{P}<0.01$ vs. control. PI, propidium iodide; $\beta$-Gal, $\beta$-galactosidase.

HGC-27 cells were significantly increased following treatment with palbociclib $(0.5 \mu \mathrm{M})+$ Jagged-1/FC $(\mathrm{P}<0.01$ in all cases $)$. These results suggested that palbociclib inhibited the Notch signaling pathway in AGS and HGC-27 cells.

Jagged-1/FC reverses the effect of palbociclib on the proliferation, apoptosis, cell senescence and cell cycle progression of AGS and HGC-27 cells. As shown in Fig. 6, AGS and HGC-27 cells treated with palbociclib $(0.5 \mu \mathrm{M})$ displayed significantly inhibited proliferation, increased apoptosis, increased cell senescence and cell cycle arrest compared with the control $(\mathrm{P}<0.01)$. Compared with palbociclib $(0.5 \mu \mathrm{M})$ treatment, the proliferation of AGS and HGC-27 cells was markedly increased in the palbociclib $(0.5 \mu \mathrm{M})+$ Jagged-1/FC group $(\mathrm{P}<0.01)$, whereas apoptosis, senescence and cell cycle arrest were notably decreased $(\mathrm{P}<0.01)$. Altogether, these results suggested that palbociclib could inhibit cell proliferation and induce senescence, cell cycle arrest and apoptosis by inhibiting the Notch pathway in AGS and HGC-27 cells.

\section{Discussion}

Most patients with GC are diagnosed at an advanced stage and usually show extensive tumor infiltration and distant lymph node metastasis $(20,21)$. The overall 5-year survival rate for patients with advanced GC is $<10 \%$ (4). Thus, the identification of novel drugs and therapeutic targets for the treatment of GC is urgently needed. In the present study, palbociclib inhibited proliferation and induced senescence, cell cycle arrest and apoptosis by inhibiting the Notch pathway in GC cells.

Cell division depends on the cell cycle, which is regulated by CDKs $(22,23)$. The interaction of cyclin D with CDK4 and CDK6 promotes the phosphorylation of the retinoblastoma gene product, which in turn leads the cell cycle from the $G_{1}$ phase to the $\mathrm{S}$ phase (22). There is currently much interest in CDK6 and the closely related CDK4 kinase as targets for cancer therapy. A previous study reported that palbociclib is a highly selective CDK4/6 inhibitor that can block the transition from the $G_{1}$ to the $S$ phase of the cell cycle (24). The present 
A

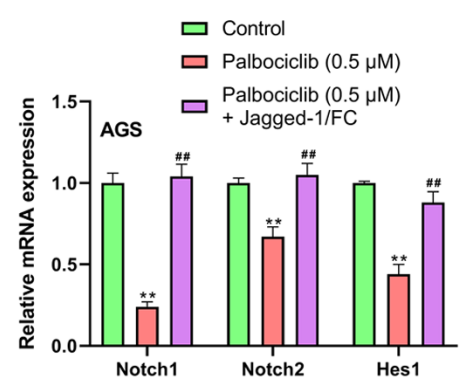

B

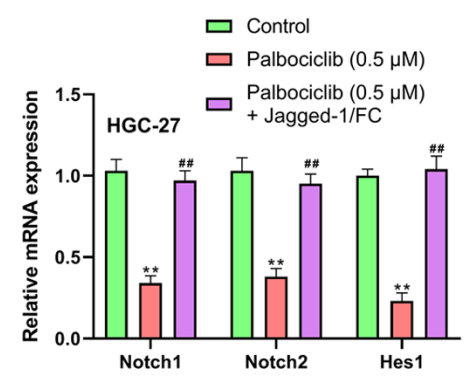

AGS

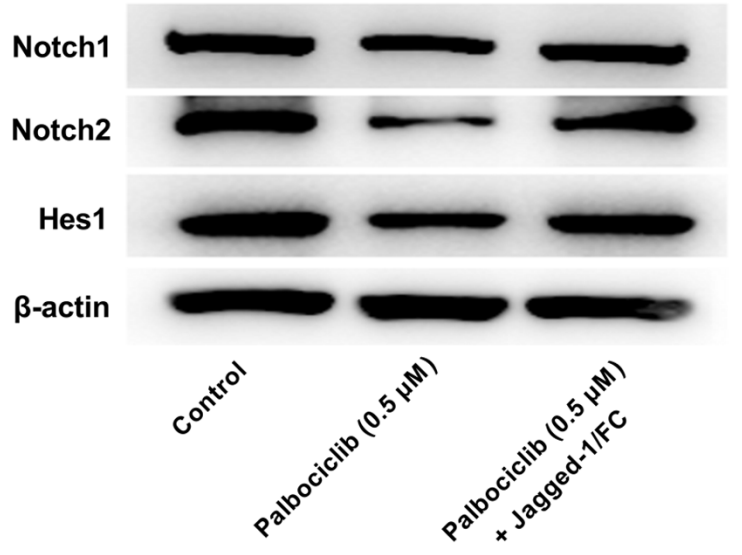

HGC-27

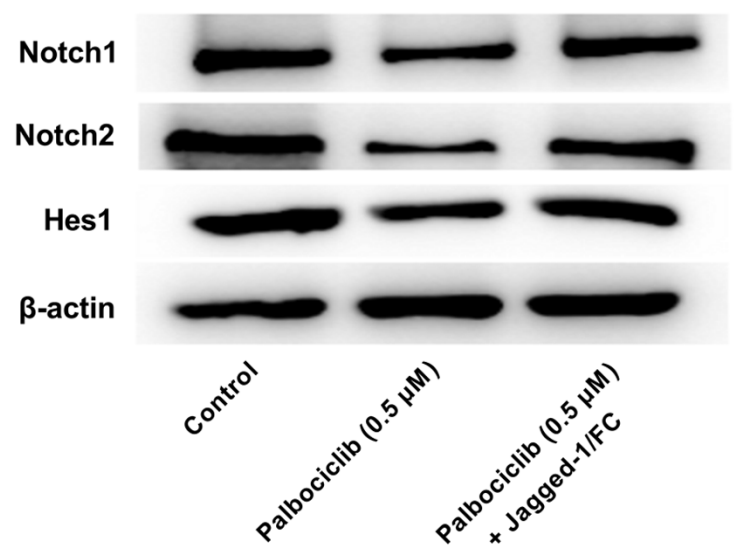

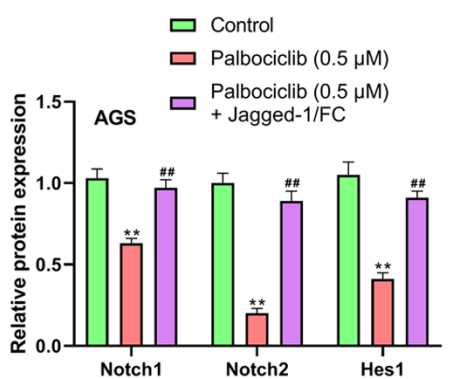

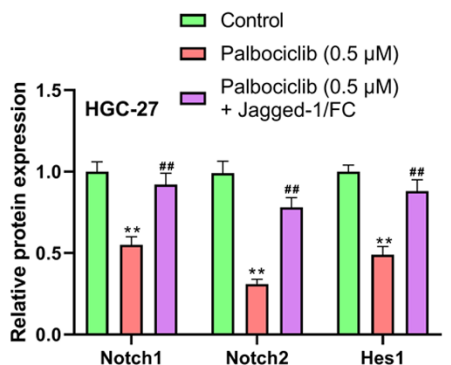

Figure 5. Palbociclib inhibits Notch signaling in AGS and HGC-27 cells. mRNA and protein expression levels of Notch1, Notch2 and Hes1 were measured in (A) AGS cells and (B) HGC-27 cells following palbociclib treatment. ${ }^{* *} \mathrm{P}<0.01 \mathrm{vs}$. control; ${ }^{\# \#} \mathrm{P}<0.01 \mathrm{vs}$. palbociclib $(0.5 \mu \mathrm{M})$. Hes1, hairy and enhancer of split 1 .

study also confirmed that palbociclib could inhibit cell proliferation and induce cell cycle arrest at the $G_{1}$ phase in GC cells in a dose-dependent manner.

In addition, a previous study also indicated that palbociclib could suppress the progression of nasopharyngeal carcinoma by mediating tumor cell apoptosis (24). Zhang et al (25) have reported that palbociclib could trigger cell apoptosis by upregulating Caspase-3 and downregulating Bcl-xl (25). The present study indicated that Palbociclib might facilitate GC cell apoptosis in a dose-dependent manner. Moreover, palbociclib decreased Bcl-2 expression and increased the expression of Bax and Caspase-3, which is a new finding that contrasts with a study by Min et al (26).

Cell senescence plays an important role against the progression of cancers and represents another intracellular tumor-suppressive mechanism (27). Evidence indicates that cell senescence is associated with the induction of several genes, including p16, p21 and p53 (28). Previous studies have confirmed that palbociclib can induce cell senescence in several types of cancer, including hepatocellular carcinoma, breast cancer, lung cancer and glioma $(7,29,30)$. In the present study, SA- $\beta$-gal staining results suggested that palbociclib promoted GC cell senescence in a dose-dependent manner. In addition, western blot results also showed that palbociclib increased the expression levels of p16, p21 and p53 in GC cells, further confirming that palbociclib could promote $\mathrm{GC}$ cell senescence.

In mammals, the Notch pathway is mediated by four Notch receptors, Notch 1-4, and five ligands, delta-like ligand (DLL) 1, DLL3, DLL4, Jagged-1 and Jagged-2 (31,32). The Notch pathway is activated when one of these ligands binds to a Notch receptor. Once the Notch pathway is activated, the Notch receptors are cleaved, and the Notch Intracellular Domain (NICD) translocates into the nucleus to regulate downstream target genes, such as Hes1, for instance (33). Previous studies have shown Notch activation leads to activation of CDK6 in the setting of mouse or human T-cell acute lymphoblastic leukemia $(34,35)$. The Notch pathway plays an oncogenic role in multiple cancer types, including hepatocellular carcinoma, glioma and breast cancer, by modulating proliferation, cell cycle, apoptosis, differentiation, senescence and metastasis $(12,36)$. Hibdon et al (37) have suggested that the activation of the Notch pathway could facilitate the proliferation of GC cells. Moreover, Notch1 and Notch2 signaling is essential for gastric stem cell proliferation in the stomach tissue of mice and humans $(38,39)$. In the present study, palbociclib significantly inhibited proliferation and induced senescence, cell cycle arrest and apoptosis by inhibiting the 
A
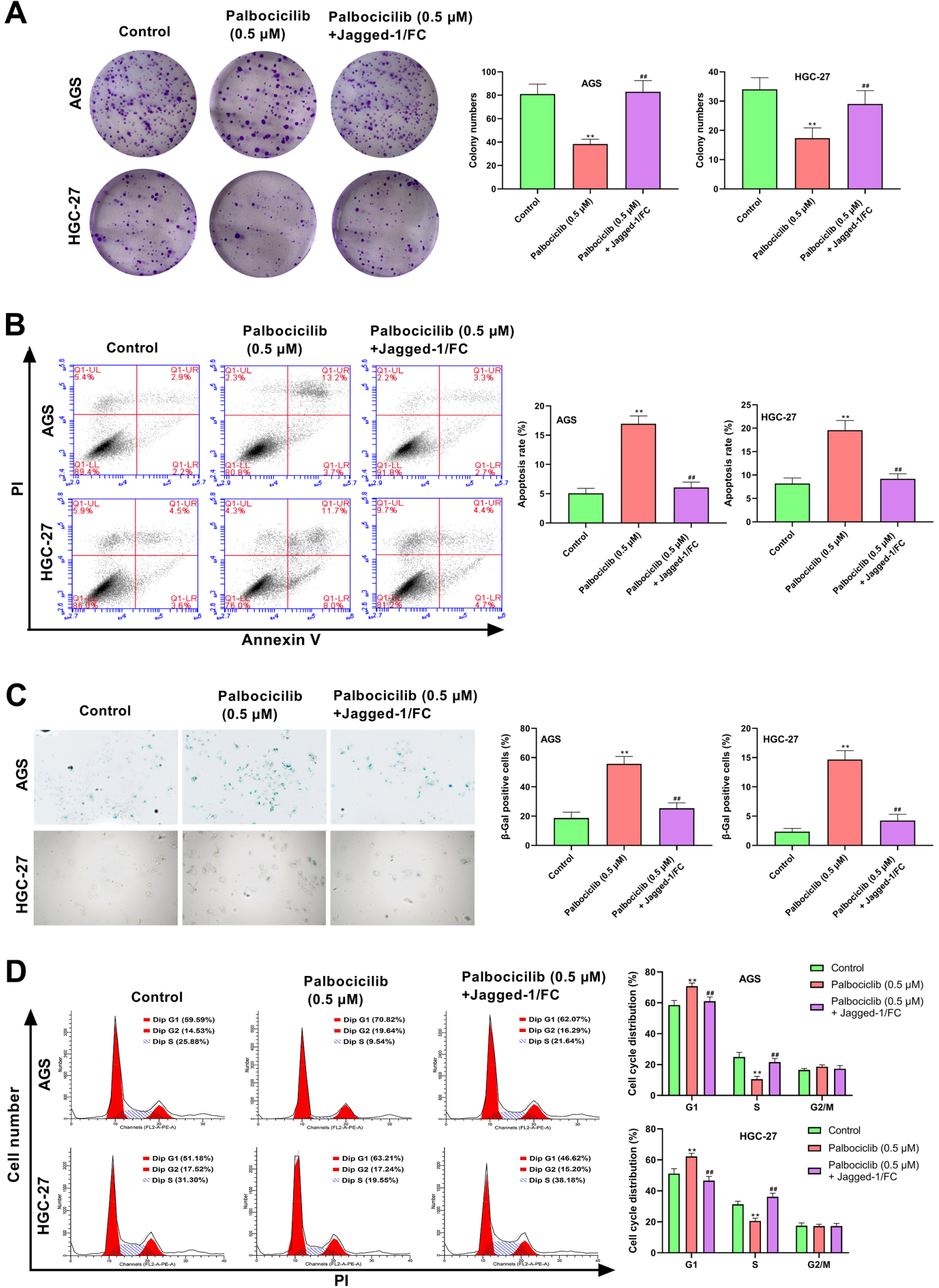

Figure 6. Jagged-1/FC reverses the effect of Palbociclib on the proliferation, apoptosis, cell senescence and cell cycle in AGS and HGC-27 cells. (A) Clone formation, (B) apoptosis, (C) senescence (magnification, x200) and (D) cell cycle progression of AGS and HGC-27 cells following treatment with palbociclib and Jagged-1/FC. ${ }^{* *} \mathrm{P}<0.01$ vs. control; ${ }^{\sharp \#} \mathrm{P}<0.01$ vs. palbociclib $(0.5 \mu \mathrm{M})$. PI, propidium iodide; $\beta$-Gal, $\beta$-galactosidase.

Notch pathway in AGS and HGC-27 cells, which highlights a new regulatory mechanism for palbociclib in GC that contrasts with a previous study (26). One of the limitations of the present study was that healthy cell lines were not used 
as a control. Furthermore, additional studies are required to determine whether palbociclib produces the same effect in other GC cell lines.

In conclusion, this study demonstrated that palbociclib could inhibit proliferation and induce senescence, cell cycle arrest and apoptosis in GC cells. In addition, the tumor-suppressive mechanism of palbociclib may be associated with the inhibition of the Notch pathway in GC. By revealing a new mechanism whereby palbociclib, regulates the Notch pathway in GC, the findings presented here not only add more data to the anticancer mechanisms of palbociclib, but also provide another option for the treatment of GC.

\section{Acknowledgements}

Not applicable.

\section{Funding}

No funding was received.

\section{Availability of data and materials}

The datasets used and/or analyzed during the current study are available from the corresponding author upon reasonable request.

\section{Authors' contributions}

YH made substantial contributions to conception and design. HB, JS, XZ and JX prepared the experimental materials and performed the experiments. $\mathrm{HB}, \mathrm{XZ}$ and JX interpreted the data, performed the statistical analysis and analyzed the results. HB revised and approved the final version of the manuscript. HB, XZ and JX confirmed the authenticity of all the raw data. All authors have read and approved the final manuscript and agree to be accountable for all aspects of the work in ensuring that the accuracy or integrity of any part of the work are appropriately investigated and resolved.

\section{Ethics approval and consent to participate}

Not applicable.

\section{Patient consent for publication}

Not applicable.

\section{Competing interests}

The authors declare that they have no competing interests.

\section{References}

1. Bray F, Ferlay J, Soerjomataram I, Siegel RL, Torre LA and Jemal A: Global cancer statistics 2018: GLOBOCAN estimates of incidence and mortality worldwide for 36 cancers in 185 countries. CA Cancer J Clin 68: 394-424, 2018.

2. Song YW, Lim Y and Cho SK: 2,4-Di-tert-butylphenol, a potential HDAC6 inhibitor, induces senescence and mitotic catastrophe in human gastric adenocarcinoma AGS cells. Biochim Biophys Acta Mol Cell Res 1865: 675-683, 2018.
3. Goscinski MA, Larsen SG, Warloe T, Stoldt S, Nesland JM, Suo ZH and Giercksky KE: Adenocarcinomas on the rise-does it influence survival from oesophageal cancer? Scand J Surg 98: 214-220, 2009.

4. Ruf C, Thomusch O, Goos M, Makowiec F, Illerhaus G and Ruf G: Impact of neoadjuvant chemotherapy with PELF-protocoll versus surgery alone in the treatment of advanced gastric carcinoma. BMC Surg 14: 5, 2014.

5. Finn RS, Dering J, Conklin D, Kalous O, Cohen DJ, Desai AJ, Ginther C, Atefi M, Chen I, Fowst C, et al: PD 0332991, a selective cyclin D kinase 4/6 inhibitor, preferentially inhibits proliferation of luminal estrogen receptor-positive human breast cancer cell lines in vitro. Breast Cancer Res 11: R77, 2009.

6. Beaver JA, Amiri-Kordestani L, Charlab R, Chen W, Palmby T, Tilley A, Zirkelbach JF, Yu J, Liu Q, Zhao L, et al: FDA approval: Palbociclib for the treatment of postmenopausal patients with estrogen receptor-positive, HER2-negative metastatic breast cancer. Clin Cancer Res 21: 4760-4766, 2015.

7. Bollard J, Miguela V, Ruiz de Galarreta M, Venkatesh A, Bian CB, Roberto MP, Tovar V, Sia D, Molina-Sánchez P, Nguyen CB, et al: Palbociclib (PD-0332991), a selective CDK4/6 inhibitor, restricts tumour growth in preclinical models of hepatocellular carcinoma. Gut 66: 1286-1296, 2017.

8. Michel L, Ley J, Wildes TM, Schaffer A, Robinson A, Chun SE, Lee W, Lewis J Jr, Trinkaus K and Adkins D: Phase I trial of palbociclib, a selective cyclin dependent kinase 4/6 inhibitor, in combination with cetuximab in patients with recurrent/metastatic head and neck squamous cell carcinoma. Oral Oncol 58: 41-48, 2016.

9. Zhang J, Zhou L, Zhao S, Dicker DT and El-Deiry WS: The CDK4/6 inhibitor palbociclib synergizes with irinotecan to promote colorectal cancer cell death under hypoxia. Cell Cycle 16: 1193-1200, 2017.

10. Valenzuela CA, Vargas L, Martinez V, Bravo S and Brown NE: Palbociclib-induced autophagy and senescence in gastric cancer cells. Ex Cell Res 360: 390-396, 2017.

11. Bolós V, Grego-Bessa J and de la Pompa JL: Notch signaling in development and cancer. Endocr Rev 28: 339-363, 2007.

12. Giovannini C, Gramantieri L, Minguzzi M, Fornari F, Chieco P, Grazi GL and Bolondi L: CDKN1C/P57 is regulated by the notch target gene hes1 and induces senescence in human hepatocellular carcinoma. Am J Pathol 181: 413-422, 2012.

13. Hu J, Yu J, Gan J, Song N, Shi L, Liu J, Zhang Z and Du J: Notch $1 / 2 / 3 / 4$ are prognostic biomarker and correlated with immune infiltrates in gastric cancer. Aging (Albany NY) 12: 2595-2609, 2020.

14. Revandkar A, Perciato ML, Toso A, Alajati A, Chen J, Gerber H, Dimitrov M, Rinaldi A, Delaleu N, Pasquini E, et al: Inhibition of Notch pathway arrests PTEN-deficient advanced prostate cancer by triggering p27-driven cellular senescence. Nat Commun 7: $13719,2016$.

15. Piao HY, Guo S, Wang Y and Zhang J: Long noncoding RNA NALT1-induced gastric cancer invasion and metastasis via NOTCH signaling pathway. World J Gastroenterol 25: 6508-6526, 2019.

16. Jena N, Sheng J, Hu JK, Li W, Zhou W, Lee G, Tsichlis N, Pathak A, Brown N, Deshpande A, et al: CDK6-mediated repression of CD25 is required for induction and maintenance of Notch1-induced T-cell acute lymphoblastic leukemia. Leukemia 30: 1033-1043, 2016.

17. Dong X, Hu X, Chen J, Hu D and Chen LF: BRD4 regulates cellular senescence in gastric cancer cells via E2F/miR-106b/p21 axis. Cell Death Dis 9: 203, 2018.

18. Schmittgen TD and Livak KJ: Analyzing real-time PCR data by the comparative C(T) method. Nat Protoc 3: 1101-1108, 2008.

19. Yang Q, Xu S, Li X, Wang B, Wang X, Ma D, Yang L, Peng J and Hou M: Pathway of Toll-like receptor 7/B cell activating factor/B cell activating factor receptor plays a role in immune thrombocytopenia in vivo. PLoS One 6: e22708, 2011.

20. Karimi P, Islami F, Anandasabapathy S, Freedman ND and Kamangar F: Gastric cancer: Descriptive epidemiology, risk factors, screening, and prevention. Cancer Epidemiol Biomarkers Prev 23: 700-713, 2014.

21. Dassen AE, Dikken JL, van de Velde CJ, Wouters MW, Bosscha $\mathrm{K}$ and Lemmens VE: Changes in treatment patterns and their influence on long-term survival in patients with stages I-III gastric cancer in The Netherlands. Int J Cancer 133: 1859-1866, 2013. 
22. Finn RS, Martin M, Rugo HS, Jones S, Im SA, Gelmon K, Harbeck N, Lipatov ON, Walshe JM, Moulder S, et al: Palbociclib and letrozole in advanced breast cancer. N Engl J Med 375: 1925-1936, 2016.

23. Lim S and Kaldis P: Cdks, cyclins and CKIs: Roles beyond cell cycle regulation. Development 140: 3079-3093, 2013.

24. Xie X, Zheng W, Chen T, Lin W, Liao Z, Liu J and Ding Y: CDK4/6 inhibitor palbociclib amplifies the radiosensitivity to nasopharyngeal carcinoma cells via mediating apoptosis and suppressing DNA damage repair. Onco Targets Ther 12: 11107-11117, 2019.

25. Zhang G, Ma F, Li L, Li J, Li P, Zeng S, Sun H and Li E: Palbociclib triggers apoptosis in bladder cancer cells by Cdk2-induced Rad9-mediated reorganization of the Bak.Bcl-xl complex. Biochem Oharmacol 163: 133-141, 2019.

26. Min A, Kim JE, Kim YJ, Lim JM, Kim S, Kim JW, Lee KH, Kim TY, Oh DY, Bang YJ and Im SA: Cyclin E overexpression confers resistance to the CDK4/6 specific inhibitor palbociclib in gastric cancer cells. Cancer Lett 430: 123-132, 2018.

27. Hornsby PJ: Senescence as an anticancer mechanism. J Clin Oncol 25: 1852-1857, 2007.

28. Cagnol S and Chambard JC: ERK and cell death: Mechanisms of ERK-induced cell death-apoptosis, autophagy and senescence. FEBS J 277: 2-21, 2010.

29. Kovatcheva M, Liu DD, Dickson MA, Klein ME, O'Connor R, Wilder FO, Socci ND, Tap WD, Schwartz GK, Singer S, et al: MDM2 turnover and expression of ATRX determine the choice between quiescence and senescence in response to CDK4 inhibition. Oncotarget 6: 8226-8243, 2015.

30. Puyol M, Martin A, Dubus P, Mulero F, Pizcueta P, Khan G Guerra C, Santamaría D and Barbacid M: A synthetic lethal interaction between K-Ras oncogenes and Cdk4 unveils a therapeutic strategy for non-small cell lung carcinoma. Cancer Cell 18: 63-73, 2010

31. Ntziachristos P, Lim JS, Sage J and Aifantis I: From Fly wings to targeted cancer therapies: A centennial for notch signaling. Cancer Cell 25: 318-334, 2014.
32. Espinoza I and Miele L: Notch inhibitors for cancer treatment. Pharmacol Ther 139: 95-110, 2013

33. Yuan X, Wu H, Xu H, Xiong H, Chu Q, Yu S, Wu GS and Wu K Notch signaling: An emerging therapeutic target for cancer treatment. Cancer Lett 369: 20-27, 2015.

34. Li N, Fassl A, Chick J, Inuzuka H, Li X, Mansour MR, Liu L, Wang H, King B, Shaik S, et al: Cyclin C is a haploinsufficient tumour suppressor. Nat Cell Biol 16: 1080-1091, 2014.

35. Joshi I, Minter LM, Telfer J, Demarest RM, Capobianco AJ, Aster JC, Sicinski P, Fauq A, Golde TE and Osborne BA: Notch signaling mediates $\mathrm{G} 1 / \mathrm{S}$ cell-cycle progression in $\mathrm{T}$ cells via cyclin D3 and its dependent kinases. Blood 113: 1689-1698, 2009.

36. Xiu MX, Liu YM and Kuang BH: The oncogenic role of Jagged1/ Notch signaling in cancer. Biomed Pharmacother 129: 110416, 2020.

37. Hibdon ES, Razumilava N, Keeley TM, Wong G, Solanki S, Shah YM and Samuelson LC: Notch and mTOR signaling pathways promote human gastric cancer cell proliferation. Neoplasia 21: 702-712, 2019.

38. Demitrack ES, Gifford GB, Keeley TM, Horita N, Todisco A, Turgeon DK, Siebel CW and Samuelson LC: NOTCH1 and NOTCH2 regulate epithelial cell proliferation in mouse and human gastric corpus. Am J Physiol Gastrointest Liver Physiol 312: G133-G144, 2017.

39. Gifford GB, Demitrack ES, Keeley TM, Tam A, La Cunza N, Dedhia PH, Spence JR, Simeone DM, Saotome I, Louvi A, et al: Notch1 and Notch2 receptors regulate mouse and human gastric antral epithelial cell homoeostasis. Gut 66: 1001-1011, 2017.

cc) (i) $\ominus$ This work is licensed under a Creative Commons (c) $\mathrm{EY}$ NO NO Attribution-NonCommercial-NoDerivatives 4.0 International (CC BY-NC-ND 4.0) License. 